\title{
The Effectiveness of Android-Based Mobile Applications Authorized Early Detection on User Satisfaction (Parents, Health Empowerment, Teacher)
}

\author{
Donni Prakosha; Supriyadi; Vania Martha Yunita \\ Sebelas Maret University, Indonesia, Indonesia \\ http://dx.doi.org/10.18415/ijmmu.v8i9.2994
}

\begin{abstract}
The 4.0 era education system requires the use of technology in pre-school and school activities. This study focuses on comparing the use of androin-based mobile applications for early detection of autism on user satisfaction (parents, health empowerment, teacher). This study was a quasi-experimental study with a post-test only control group design. A total of 30 parents, 30 health empowerment, and 30 educators in the city of Surakarta who were selected by purposive sampling were used as research samples. The samples were classified into two groups, namely by using an android-based mobile application for early detection of autism. User satisfaction data is collected through a user satisfaction questionnaire. Data were analyzed using univariate and bivariate with mann withney in the SPSS program. The results showed the influence of androin-based mobile applications early detection of autism on user satisfaction. The satisfaction of teaching staff users is higher than that of health empowerment and parents.
\end{abstract}

Keywords: Mobile Application; Early Detection of Autism; User Satisfaction; Quasi Experiment

\section{Introduction}

Autism Spectrum Disorder (ASD) is a neurodevelopmental disorder associated with a lack of social interaction, communication and behavior. Children with autism are usually represented by repetitive, narrow interests, stereotyped behaviors and activities. According to the Diagnostic and Statistical Manual of Mental Disorders Version 5 (DSM5), autism is diagnosed by investigating deficits in social communication, repetitive behavior patterns, inappropriate responses during conversation and lack of verbal and nonverbal interactions with others. In this situation, they cannot make themselves comfortable in their social environment and their environmental behavior remains unnoticed for a long time until they reach the group (Satu et al, 2019).

Statistics on the prevalence of ASD were studied among 10 countries (per 10,000 children) in which the United States was estimated to have the highest autism rate (161 children) [3]. Furthermore, about 1.5\% of the world Identification of funding institutions that apply here. If it's not there, delete it. the population contains ASD and it is believed that a very large number of individuals remain undetectable from this spectrum. For early detection, many existing screening tools to detect ASD in various countries (Satu et al, 2019).

Among the revised versions of M-CHAT, M-CHATR / F has been represented as the standard of advanced technology recently. All of them detected ASD by investigating individual questionnaires and the children's physical activity. Many well-developed mobile applications exist that can effectively screen and detect autism in children. However, most built in developed tools and updated treatments are available to detect ASD. In a developing country like Bangladesh, such detectors seem inconvenient for people. However, they do not care about this type of neurological disease and are hesitant to go to a doctor or 
healthcare professional to diagnose autism. It is also time consuming and expensive to detect autism by traditional screening processes. Smartphones are one of the most common electronic devices which can be used as ideal platforms for autism screening. In this regard, we have developed a smartphone-based application called 'Prottoy' in which children aged 3 to 11 years are considered to screen for and identify autism (Satu et al, 2019).

The global prevalence of mental disorders in the world is estimated at 13\%. Among them, the prevalence of anxiety disorders in children and adolescents, although the variability of the studies varies, is reported to be around $6.5 \%$, with the highest prevalence among all psychiatric disorders. One of the earliest anxiety disorders is Separation Anxiety Disorder (SAD), which is defined as an abnormal response to the real or imagined separation of the individual under attachment, which interferes with its normal function (Mohammadi et al, 2020).

Cellular technology and wireless sensors are changing the way we live our lives and the way we perceive our environment. Today, cell phones and tablets have the ability to recognize facial expressions, and wireless biosensors can measure arousal, attention and meditation levels. This new capability provides a real opportunity to create a new range of emotionally aware applications. One target group that would benefit greatly from emotionally conscious applications are children with Autism Spectrum Disorder (ASD). ASD describes a variety of conditions that are usually characterized by social deficits, communication difficulties, stereotypical or repetitive behaviors and interests, and in some cases, cognitive delays (Gay \& Leiddekker, 2014).

There is currently an increasing social incentive worldwide to educate those with special needs or (special educational needs) with their non-disabled peers in mainstream educational settings. United Nations Educational, Scientific and Cultural Organization (UNESCO, 1994).

The main factors reported by parents in sending their children to mainstream settings were social learning and active participation. Indeed, it is argued that full inclusion also includes participation (social, emotional and academic) and acceptance by teachers and peers (Morris et al, 2020).

The prevalence of anxiety disorders, and in particular separation anxiety disorder, has been studied and evaluated in various studies. The prevalence varies according to the survey method and the type of instrument used. For example, several studies reported a one-year prevalence of separation anxiety disorder of $4.3 \%$. Also, some tests have reported a different prevalence of anxiety disorders among boys and girls, while some studies report no difference in prevalence between the two groups (Mohammadi et al, 2020).

Although autism spectrum disorder (ASD) is a neurodevelopmental condition that most likely begins during the prenatal period, there are currently no behavioral measures that can be used to identify children at risk of developing the disorder early in development. Atypical behavior patterns in several domains, including responses to social stimuli (Tenebaum et al, 2020).

The strongest determinant of variability in prevalence estimates is the screening tool used, and it is found that studies using the Autism Behavior Checklist (ABC), and the Clancy Autism Behavior Scale (CABS) (17), resulted in lower prevalence estimates, while studies using the Checklist for Autism in Toddlers (CHAT), reported higher prevalence estimates for autism. Age at screening is also another strong determinant of estimated prevalence. Fifteen of the 18 studies focused on children who were screened between the ages of 2-6 years and the other seven focused on children aged 6-14 years and over (Barbaro et al, 2020). 


\section{Method}

\section{Research Design}

This study used a quasi-experimental method with a post-test only control group design. The samples were classified into two groups, namely by using an android-based mobile application for early detection of autism. User satisfaction data is collected through a user satisfaction questionnaire. The independent variable of this study was a mobile application based on andoid for early detection of autism. The dependent variable in this study is user satisfaction. This research is focused on comparing the use of technology-based media. So, there are three groups, each of which is divided into two for testing the use of android-based mobile applications for early detection of autism and manual early detection of autism. The research design of this study is described in Table 1.

Table 1. Overview of Research Design

\begin{tabular}{llll}
\hline \multirow{2}{*}{ Group } & Treatment & Post-test of User \\
\cline { 2 - 4 } & $\begin{array}{l}\text { Android based mobile } \\
\text { application }\end{array}$ & Manual & Satisfaction \\
\hline Parents & Yes & Yes & Yes \\
Health empowerment & Yes & Yes & Yes \\
Teacher & Yes & Yes & Yes \\
\hline
\end{tabular}

\section{Research Samples}

The population in this study includes all parents, cadres, and educators who have the same characteristics in the city of Surakarta, Central Java, Indonesia. The population characteristics in this study are to behave to communicate and interact in the online phase, the age of children under five, use Indonesian, and have adequate facilities to support Android-based mobile applications. The sample of this research was 20 parents who were taken from kindergarten / early childhood guardians, 20 Posyandu cadres, and teaching staff from all over Surakarta City using purposive sampling.

\section{Research Instruments}

Before the research instrument is applied, first the instrument is tested for validity and reliability testing purposes. The validity test according to Murti (2018) states that the validity of measuring an instrument is the degree of ability (performance) in capturing what should be measured, whether shown theoretically-conceptually or empirically. Content validity is the degree of relevance and coverage of the content.

The validity of the content in which the questionnaire is assessed by checking the question items in the questionnaire is whether the content of the variables studied is appropriate. Conducting content validity can be done by an expert who already knows the knowledge to give his opinion (subjective) to the entire content which is often referred to as validity by assumption (Strainer and Nurman in Murti 2016). Face validity refers to the degree of conformity of the external appearance of the measuring instrument and the measured variables. Facial validity is a check of language and sentence effectiveness so that the sentence is not ambiguous or confusing and can answer what the researcher wants (Murti, 2013).

Reliability test is done by testing the instrument by calculating the total item correlation and Alpha Cronbach. An item can be used as a measuring tool if it has an item-total correlation $\geq 0.20$. Items with low correlation should be discarded or rewritten. however, items with too high a correlation $(>0.90)$ also need to be re-examined because they can be caused by duplication of measurements so that one item must be removed. 
Half-part reliability assesses the internal consistency (homogeneity) of the measuring instrument by dividing the items randomly into two parts of the measuring instrument and then correlating the two parts. The reliability of the halves is indicated by the Cronbach Alpha value. The minimum Cronbach Alpha value for a measuring instrument is 0.60. The higher the Cronbach Alpha, the better (consistent) a measuring instrument is.

\section{Research Procedure}

The use of an Android-based mobile application for early detection of autism was carried out. Each group used two different interventions. The parent group initially used a manual checklist in early detection of autism and then later used a mobile application. The same is the case with the cadre group and educators. The research was conducted by visiting the homes of kindergarten and early childhood students due to the online system during the pandemic. Researchers combed the samples using health protocols. Filling in the instrument and questionnaire was carried out at the house of each sample group.

\section{Data Analysis}

The normality test is used in testing whether the distribution of the dependent variable for each value of certain independent variables has a normal distribution or not. In the linear regression model, this assumption is indicated by the error value $(\square)$ which are normally distributed. A good regression model is a regression model that has a normal distribution or is close to normal, so it is worth testing statistically. Data normality testing used the Kolmogorov-Smirnov Test of Normality in the SPSS program.

This partial correlation analysis is used to determine the strength of the relationship between the correlation between the two variables where the other variables that are considered influential are controlled or fixed (as control variables). Because the variables studied were interval data, the statistical technique used was Pearson Correlation Product Moment.

Parametric statistical tests used the non-parametric Mann Withney test because the data were not normally distributed. This test uses a significant level of 5\%, meaning that the hypothesis is accepted if the asymp sig $\leq 0.05$. The data were also tested using the Pearson correlation test to obtain an analysis of the relationship between variables.

\section{Research Procedure}

The use of an Android-based mobile application for early detection of autism was carried out. Each group used two different interventions. The parent group initially used a manual checklist in early detection of autism and then later used a mobile application. The same is the case with the cadre group and educators. The research was conducted by visiting the homes of kindergarten and early childhood students due to the online system during the pandemic. Researchers combed the samples using health protocols. Filling in the instrument and questionnaire was carried out at the house of each sample group.

\section{Data Analysis}

The normality test is used in testing whether the distribution of the dependent variable for each value of certain independent variables has a normal distribution or not. In the linear regression model, this assumption is indicated by the error value ( $\square$ ) which are normally distributed. A good regression model is a regression model that has a normal distribution or is close to normal, so it is worth testing statistically. Data normality testing used the Kolmogorov-Smirnov Test of Normality in the SPSS program. 
This partial correlation analysis is used to determine the strength of the relationship between the correlation between the two variables where the other variables that are considered influential are controlled or fixed (as control variables). Because the variables studied were interval data, the statistical technique used was Pearson Correlation Product Moment (Sugiyono, 2013: 216).

Parametric statistical tests used the non-parametric Mann Withney test because the data were not normally distributed. This test uses a significant level of 5\%, meaning that the hypothesis is accepted if the asymp sig $\leq 0.05$. The data were also tested using the Pearson correlation test to obtain an analysis of the relationship between variables.

\section{Results and Discussion}

\section{Result}

According to the descriptive data in table 2, it shows that for customer satisfaction the parent subjects have a mean of 0.38 with a standard deviation of 0.49 . In the research subjects, the posyandu cadres show a mean of 0.51 and a standard deviation of 0.51 . The subject of teaching personnel had a mean of 0.55 and a standard deviation of 0.51 .

Table 2. Descriptive Table of Research Samples

\begin{tabular}{lccc}
\hline Group & N & Mean & SD \\
\hline Parents & 60 & 0.41 & 0.49 \\
$\begin{array}{l}\text { Health } \\
\text { Empowerment }\end{array}$ & 60 & 0.51 & 0.51 \\
$\begin{array}{l}\text { Teacher } \\
\text { Pen }\end{array}$ & 60 & 0.55 & 0.51 \\
\hline
\end{tabular}

Table 3 shows the data normality test analysis using the One-Sample Kolmogorov-Smirnov test. Based on the table, the distribution of data on the type of intervention shows results with a significant probability value, namely $<0.001$, so it is said that the data is not normal. The distribution of user satisfaction data with the parent group shows results with a significant probability value, namely $<0.001$, so it is said that the data is not normal. The distribution of user satisfaction data with community health empowering groups shows results with a significant probability value of $<0.001$, so it is said that the data is not normal. The distribution of user satisfaction data with the group of educators shows results with a significant probability value, namely $<0$.

Table 3. Data on the results of the One-Sample Kolmogorov-Smirnov Normality Test

\begin{tabular}{llllll}
\hline Data group & $\mathbf{N}$ & Mean & SD & P Value & Distribution \\
\hline Intervention & 60 & 0.50 & 0.51 & $<0.001$ & No N \\
$\begin{array}{l}\text { Parents } \\
\begin{array}{l}\text { Health } \\
\text { empowerment }\end{array}\end{array}$ & 60 & 0.42 & 0.49 & $<0.001$ & No N \\
Teacher & 60 & 0.52 & 0.51 & $<0.001$ & No N \\
\hline
\end{tabular}

Table 4 shows the analysis of the relationship between groups of parents, cadres, and educators whose satisfaction is calculated on the use of android-based mobile applications for early detection of autism. ui pearson produced an average of 0.42 points for parents, for a cadre average of 0.52 points, and 
an average of 0.55 points for teaching staff. Then the results of the Pearson correlation test showed that all groups were associated with the results $\mathrm{p}$ value $<\alpha(\alpha<0.05)$.

Table 4. Pearson correlation test table between research groups of parents, cadres, and teaching staff with the mobile application for early detection of autism and manual early detection.

\begin{tabular}{|c|c|c|c|c|c|}
\hline Group & & $\mathbf{N}$ & Mean & SD & P Value \\
\hline Parents & & 60 & 0.42 & 0.49 & $<0.001$ \\
\hline $\begin{array}{l}\text { Community } \\
\text { personnel }\end{array}$ & empowerment & 60 & 0.52 & 0.51 & 0.004 \\
\hline Teacher & & 60 & 0.55 & 0.50 & 0.001 \\
\hline
\end{tabular}

Furthermore, the results of the calculation of the correlation coefficient are carried out through the SPSS application program. The criterion used is if the p value is greater ( $>$ ) than the value $\alpha$ In particular, the hypothesis proposed in this study is rejected, meaning that there is no significant relationship between the android-based mobile application variables for early detection of autism and patient satisfaction in 3 trial groups (parents, cadres, and teachers). Conversely, if the $\mathrm{p}$ value is smaller than the value $\alpha$ Of course the hypothesis in this study is accepted, meaning that there is a significant relationship between androidbased mobile application variables for early detection of autism and patient satisfaction in 3 trial groups (parents, cadres, and teachers).

Patient satisfaction with the Android-based mobile application for early detection of autism in the parent group, the correlation with the SPSS program in the table shows that the $\mathrm{p}$ value is smaller than $\alpha$ used is (0.05), namely: $<0.001$. Patient satisfaction with the Android-based mobile application for early detection of autism in the community health empowerment group, the correlation with the SPSS program in the table shows that the $\mathrm{p}$ value is smaller than the $\alpha$ used is (0.05), namely: 0.004. Patient satisfaction with the Android-based mobile application for early detection of autism in the group of educators, the correlation with the SPSS program in the table shows that the $\mathrm{p}$ value is smaller than $\alpha$ used is (0.05), namely: 0.001 .

Table 4 shows the frequency of customer satisfaction on the use of an Android-based mobile application for early detection of autism with the parent study subjects with a sample of $60,36 \%$ were dissatisfied and $63 \%$ were satisfied. The frequency of customer satisfaction on the use of android-based mobile applications for early detection of autism with research subjects who empower public health with a sample of 60 as much as 30\% who are not satisfied and $70 \%$ are satisfied. The frequency of customer satisfaction on the use of android-based mobile applications for early detection of autism with the research subjects of teaching staff with a sample of 60 was 33\% who were dissatisfied and $66 \%$ were satisfied.

Table 4. Table of Crosstab Analysis Results and Mann Withney Test

\begin{tabular}{cccccccc}
\hline & \multirow{2}{*}{ Group } & \multirow{2}{*}{$\mathbf{N}$} & \multicolumn{2}{c}{ Not satisfied } & \multicolumn{2}{c}{ Satisfied } & \multirow{2}{*}{ p value } \\
\cline { 5 - 7 } Parents & Mobile Apps & 30 & 11 & 36 & 19 & 63 & \multirow{2}{*}{0.001} \\
& Manual & 30 & 24 & 80 & 6 & 20 & \\
\multirow{3}{*}{ Cadre } & Mobile Apps & 30 & 9 & 30 & 21 & 70 & \multirow{2}{*}{0.005} \\
& Manual & 30 & 20 & 66 & 10 & 33 & \\
& Moble Apps & 30 & 10 & 33 & 20 & 66 & \multirow{2}{*}{0.001} \\
\hline
\end{tabular}

The Mann Withney test in this study showed a high significance for each respondent $(\mathrm{p}<0.05)$. The highest significance in the study subjects parents and educators who are both 0.001 . Then for the next cadre with a significant value of 0.005 . The satisfaction variable in the parent group with the Android-based mobile application for early detection of autism has a significant value of $\mathrm{p}<0.05(\mathrm{P}=0.001)$. The 
satisfaction variable in the community health empowerment group towards android-based mobile applications for early detection of autism has a significant value of $\mathrm{p}<0.05(\mathrm{P}=0.005)$. On the satisfaction variable in the group of educators with Android-based mobile applications for early detection of autism has a significant value of $\mathrm{p}<0.05(\mathrm{P}=0.001)$.

\section{Discussion}

This section describes its discussion of the findings of this study. This study suggests significant results regarding the differences in autism screening using an android-based mobile application for early detection of autism with manual early detection. As the latest developments in science and technology, the quality of screening depends on the skills of assistants, educators and parents in mastering technology. These skills can help the need to create a teaching environment for children with disabilities that will adjust to how deep their autistic level is in the pre-school education process (Kuzminska et al, 2017).

In line with this study, Duda et al (2016) state that the Cellular Autism Risk Assessment (MARA) is periodic, and can determine whether a child is at risk for Autism. MARA consists of seven things (for example, "Can your child have back and forth conversations with you?" Or "Does your child engage in imaginative play or fakes?") That ask about the child's communication, social skills, and behavior and can used in any device that is connected to the Internet is very effective used for autism screening (Duda et al, 2016).

Tariq et al $(2018,2019)$ also argued that the same thing in studies in the United States and Bangladesh resulted in high test accuracy in addition to some positive sensitivity and specificity in autistic screening using mobile phones. In the US clinical sample, testing accuracy was rated above $90 \%$ across all eight classifier mobile phone screening questionnaires with a sensitivity at or above $94.5 \%$ for each model. However, its specificity was noted to be low, with only three out of eight classifiers at or above $50 \%$.

Smith et al. (2017), conducted a screening approach with NODA and IPA examined through calculating the percentage agreement sensitivity and specificity calculated for the full sample (N 51) and for a sub-sample of children suspected of having ASD (N 40). The diagnostic deal was $88.2 \%(0.75)$ in the full sample and $85 \%(0.58)$ in the ASD-specific sample. The sensitivity was $84.9 \%$ for both, while the specificity was $94.4 \%$ in the full sample and $85.7 \%$ in the ASD only sample.

The key to screening the parent questionnaire on behavior patterns was similar to that examined by the standard autism diagnostic instrument, the Revised Autism Diagnostic Interview (ADIR). Clinically, this tool consists of parent interviews with 93 multi-part multi-choice questions and numerical responses submitted by trained professionals in the clinical setting. While this instrument is considered the primary standard, and provides consistent results across examiners, the cost and time to set it up is prohibitive in the primary care setting. The approach to using clinical ADIR instrument data to create a screener based on a short questionnaire presented directly to parents without supervision has resulted in high effectiveness (Abbas et al, 2017).

ADOS (Autism Diagnostic Observation Schedule) is widely regarded as the gold standard and is one of the most commonly used behavioral instruments to aid in the diagnosis of autism. 8 This examination consists of an interactive and structured examination of a child by a trained doctor in a tightly controlled setting. ADOS is a multi-modular diagnostic instrument, with different modules for subjects at different levels of cognitive development. In this paper, we present our approach to mining ADOS clinical records, with a focus on younger developmental ages, to create a video-based screener that relies on analysts evaluating children's videos recorded by their parents at home.

Our findings also suggest that the observed increase in ASD prevalence is largely due to the increase in ASD diagnosed in certain age groups, with the greatest increases observed in toddlers and 
preschool children. Since early detection of ASD is considered to allow more effective interventions (Davidovitch et al, 2020).

Addition of specific feeding behavior question points to ASD-specific screening instruments such as M-CHAT, SCQ and CoSoS. may be of help in providing a more complete ASD phenotype. The addition of such points can also increase the validity of the instrument (Van et al, 2021).

Screening assessments via mobile apps or marriage are another approach to more intensive behavioral measures. This methodology involves completing the ranking participants at various times throughout the day when requested. When assessments are delivered via telephone message or on a website, parents or children who only have access to mobile phones can complete the screening relatively easily and quickly. Assessment may include measuring the current self-reported symptoms in their natural environment. Current assessments offer many advantages, as they provide a unique perspective on parental experiences (Dahiya et al 2020).

Delehanty et al, (2020) revealed that using cell phones in early detection of autistic behavior is not very effective. Completion of early detection manually and face to face without using cell phones by educators and health workers is more effective.

Teachers who teach children with disabilities cannot work in a pre-planned form as they are usually developing one. Work ambiguity is more aimed at those who teach children with autism, given the heterogeneity and dynamic nature of the disorder (Ogba et al, 2020). Therefore, educators here are prepared from the start for screening children so that they can teach the right method according to the child's autism level.

Acar's (2020) study examined Turkish teacher assessments of developing student exclusion from students with ASD, and teachers' failure to include students, using a social domain theory framework. There are two sets of findings. The first series explored pre- and occupational teacher assessments of the exclusion of fourth-grade students with ASD by peers. The second set examines the teacher's view of the protagonist teacher's failure to include students. Teachers distinguished context exceptions when they evaluated typically developing student exclusion from students with ASD. Teachers tended to rate student exclusion from science projects more negatively than exclusion from ball games during recess.

Infants and children need care and available care to meet their physical and psychological development needs.9 The quality and consistency of care influences behavioral patterns for attention, emotions and social relationships from birth. Babies and children depend on development. Childhood outcomes are sensitive to parental attention, responsiveness, model behavior, and family / cultural environment (Beamish et al, 2018).

Parents' experience in participating using mobile phones in determining the comparison of mental health problems and stress levels from an early age. This lack of social experience affects parents in training children with ASD so that they lack support in training children to interact (Shoostari et al, 2020).

Some of the defining characteristics of ASD, such as deficits in social and communication skills, may make it difficult for such children to obey general instructions. In a school setting, the persistently low level of understanding of the teaching force can adversely affect students' ability to develop social and academic skills appropriate to their needs. In addition, the problem of understanding the needs of children with autism can also cause significant pressure on teachers and limit educational opportunities for other students in the class (Imasaka et al, 2019). 
A number of intervention programs have been developed to address the needs of children. Common restrictions include requirements for skilled procedural implementation by others (for example, parents or teachers) and low rates of treatment (Imasaka et al, 2019).

Given the limitations of this strategy in academic settings, further research exploring alternative treatments appears necessary. Ideally, such a strategy should be characterized by ease of implementation, with less dependence on encouragement by adults. More precisely, these characteristics will make the intervention attractive to teachers giving them more time for academic instruction and less need for behavior management (Imasaka et al, 2019).

Various interventions have been tried in research studies on early detection of autism in schools, from pre-school to adolescents. These studies have explored various things. Educational approaches for special teachers in teaching children with autism, and an integrated model is developed that meets the individual needs of these children. The important role of teacher specialists has also been underlined. However, some specialist teachers were found to lack confidence in working with children with ASD due to a lack of preparation, leading to decreased teaching effectiveness (Jung \& Lee, 2020).

In a Greek study, special education teachers were confused about the teaching methods used in special education, even though they had better knowledge of ASD than general education teachers. Interventions for aggressive behavior in people with ASD have used a behavioral focus to improve safety and educational skills in real-world settings. Meanwhile, the advanced VR technology has resulted in increasing research on VR based training and simulation content applications. Compared to VR-based training, repeated education in real-world settings is reported to be less stimulating and engaging, so that children with ASD are immersed in learning [17-19]. Hence, exploring new approaches to aggression management in children and adolescents with autism.

In this study, we conducted semi-structured interviews to identify specific teacher perceptions about the aggressive management of behavior of children and adolescents with ASD, with the ultimate goal of providing implications for the development of aggression management training programs and enhancement of teacher competencies (Jung \& Lee, 2020).

\section{Conclusion}

From the results and discussion in this study, it can be concluded that the Android-based mobile application for early detection of autism today can be more effectively used than manually. We can present from various sides with the educational side that we take from the teacher, in terms of family approach represented by parents and from a public health perspective with representatives of community health empowerment agencies. For the highest effectiveness were parents and teachers $(p=0.001)$, then the health empowerment cadres $(\mathrm{p}=0.005)$.

\section{References}

Abbas, H., Garberson, F., Glover, E., \& Wall, DP (2017). Machine learning approach for early detection of autism by combining questionnaire and home video screening. ArXiv, 3558-3561.

Pickles, M. (2020). Turkish teachers' social judgments on autism spectrum-based exclusion in primary schools. British Journal of Special Education.https://doi.org/10.1111/1467-8578.12327

Barbaro, J., Wang, C., Wang, J., Liu, G., Liang, Y., Wang, J.,... Dissanayake, C. (2020). A Pilot Investigation of the Social Attention and Communication Surveillance (SACS) Tool for the Early 
Identification of Autism in Tianjin, China (SACS-C). Frontiers in Neurology, 11 (November). https://doi.org/10.3389/fneur.2020.597790

Beamish, N., Fisher, J., \& Rowe, H. (2019). Parents' use of mobile computing devices, caregiving and the social and emotional development of children: a systematic review of the evidence. Australasian Psychiatry, 27 (2), 132-143. https://doi.org/10.1177/1039856218789764

Chen, LW, Wang, ST, Wang, LW, Kao, YC, Chu, CL, Wu, CC,... Huang, CC (2020). Early neurodevelopmental trajectories for autism spectrum disorder in children born very preterm. Pediatrics, 146 (4). https://doi.org/10.1542/peds.2020-019232

Dahiya, AV, McDonnell, C., DeLucia, E., \& Scarpa, A. (2020). A systematic review of remote telehealth assessments for early signs of autism spectrum disorder: Video and mobile applications. Practice Innovations, 5 (2), 150-164. https://doi.org/10.1037/pri0000121

Daniels, J., Schwartz, J., Albert, N., Du, M., \& Wall, DP (2017). The GapMap project: a mobile surveillance system to map diagnosed autism cases and gaps in autism services globally. 4-9. https://doi.org/10.1186/s13229-017-0163-7

Davidovitch, M., Slobodin, O., Weisskopf, MG, \& Rotem, RS (2020). Age-Specific Time Trends in Incidence Rates of Autism Spectrum Disorder Following Adaptation of DSM-5 and Other ASDRelated Regulatory Changes in Israel. Autism Research, 13 (11), 1893-1901. https://doi.org/10.1002/aur.2420

Delehanty, A., Lee, J., Hooker, JL, Cortese, J., \& Woods, J. (2020). Exploring message framing to engage parents in early screening for autism spectrum disorder. Patient Education and Counseling, 103 (12), 2525-2531. https://doi.org/10.1016/j.pec.2020.06.024

Engelhard, MM, Berchuck, SI, Garg, J., Henao, R., Olson, A., Rusincovitch, S.,... Kollins, SH (2020). Health system utilization before age 1 among children later diagnosed with autism or ADHD. Scientific Reports, 10 (1), 1-10. https://doi.org/10.1038/s41598-020-74458-2

Grayson, DR, Guidotti, A. (2016). Approaches To Better Understand Autistic Spectrum Disorder. Epigenomics, $\quad 8 \quad$ (1), 85-104. $\quad$ Retrieved from http://www.futuremedicine.com/doi/pdf/10.2217/epi.15.92

Imasaka, T., Lee, PL, Anderson, A., Wong, CWR, Moore, DW, Furlonger, B., \& Bussaca, M. (2020). Improving Compliance in Primary School Students with Autism Spectrum Disorder. Journal of Behavioral Education, 29 (4), 763-786. https://doi.org/10.1007/s10864-019-09346-5

Jung, M., \& Lee, E. (2020). Specialized teachers' perceptions on the management of aggressive behaviors in children and adolescents with autism spectrum disorders. International Journal of Environmental Research and Public Health, 17 (23), 1-13. https://doi.org/10.3390/ijerph17238775

Kalantarian, H., Jedoui, K., Dunlap, K., Schwartz, J., Washington, P., Husic, A.,... Wall, DP (2020). The Performance of Emotion Classifiers for Children With Parent-Reported Autism: Quantitative Feasibility Study. JMIR Mental Health, 7 (4), e13174. https://doi.org/10.2196/13174

Leblanc, E., Washington, P., Varma, M., Dunlap, K., Penev, Y., Kline, A., \& Wall, DP (2020). Feature replacement methods enable reliable home video analysis for machine learning detection of autism. Scientific Reports, 10 (1), 1-11. https://doi.org/10.1038/s41598-020-76874-w

McCarty, P., \& Frye, RE (2020). Early Detection and Diagnosis of Autism Spectrum Disorder: Why Is It So Difficult? Seminars in Pediatric Neurology, 35, 100831. https://doi.org/10.1016/j.spen.2020.100831

Mohammadi, MR, Badrfam, R., Khaleghi, A., Hooshyari, Z., Ahmadi, N., \& Zandifar, A. (2020). Prevalence, Comorbidity and Predictor of Separation Anxiety Disorder in Children and Adolescents. Psychiatric Quarterly, 91 (4), 1415-1429. https://doi.org/10.1007/s11126-020-09778-7

Morris, S., O'Reilly, G., \& Byrne, MK (2020). Understanding Our Peers with Pablo: Exploring the Merit of an Autism Spectrum Disorder De-stigmatization Program Targeting Peers in Irish Early Education Mainstream Settings. Journal of Autism and Developmental Disorders, 50 (12), 4385-4400. https://doi.org/10.1007/s10803-020-04464-w

Murti B (2018). Principles and Methods of Epidemiological Research, Fourth Edition. Central Java. Morning Star Offset 
Ogba, FN, Onyishi, CN, Victor-Aigbodion, V., Abada, IM, Eze, UN, Obiweluozo, PE,... Onwu, AO (2020). Managing job stress in teachers of children with autism. Medicine, 99 (36), e21651. https://doi.org/10.1097/md.0000000000021651

Qian, X., Johnson, DR, Wu, YC, LaVelle, J., Thurlow, ML, \& Davenport, E. (2020). Parents' Postsecondary Education Expectations for Students with Autism, Intellectual Disability, and Multiple Disabilities: Findings From NLTS 2012. Research and Practice for Persons with Severe Disabilities, 45 (4), 256270. https://doi.org/10.1177/1540796920962423

Satu, MS, Azad, MS, Haque, MF, Imtiaz, SK, Akter, T., Barua, L.,... Al Mamun, KA (2019). Prottoy: A Smart Phone Based Mobile Application to Detect Autism of Children in Bangladesh. 2019 4th International Conference on Electrical Information and Communication Technology, EICT 2019, (December), 1-6. https://doi.org/10.1109/EICT48899.2019.9068815

One, MS, Azad, MS, Haque, MF, Imtiaz, SK, Akter, T., Barua, L.,... Al Mamun, KA (2019). Prottoy: A Smart Phone Based Mobile Application to Detect Autism of Children in Bangladesh. 2019 4th International Conference on Electrical Information and Communication Technology, EICT 2019, (December), 1-6. https://doi.org/10.1109/EICT48899.2019.9068815

Shooshtari, MH, Zarafshan, H., Mohamadian, M., Zareee, J., Keisomi, IK, \& Hooshangi, H. (2020). The effect of a parental education program on the mental health of parents and behavioral problems of their children with autism spectrum disorder. Iranian Journal of Psychiatry and Clinical Psychology, 25 (4), 356-367. https://doi.org/10.32598/ijpcp.25.4.1

Stenhoff, DM, Pennington, RC, \& Tapp, MC (2020). Distance Education Support for Students With Autism Spectrum Disorder and Complex Needs During COVID-19 and School Closures. Rural Special Education Quarterly, 39 (4), 211-219. https://doi.org/10.1177/8756870520959658

Tenenbaum, EJ, Carpenter, KLH, Sabatos-devito, M., Hashemi, J., Vermeer, S., Sapiro, G., \& Dawson, G. (2020). RESEARCH ARTICLE A Six-Minute Measure of Vocalizations in Toddlers with Autism Spectrum Disorder. 1-10. https://doi.org/10.1002/aur.2293

Van 't Hof, M., Ester, WA, van Berckelaer-Onnes, I., Hillegers, MHJ, Hoek, HW, \& Jansen, PW (2021). Do early-life eating habits predict later autistic traits? Results from a population-based study. Appetite, 156 (September 2020), 104976. https://doi.org/10.1016/j.appet.2020.104976

Viezel, KD, Williams, E., \& Dotson, WH (2020). College-Based Support Programs for Students With Autism. Focus on Autism and Other Developmental Disabilities, 35 (4), 234-245. https://doi.org/10.1177/1088357620954369

\section{Copyrights}

Copyright for this article is retained by the author(s), with first publication rights granted to the journal.

This is an open-access article distributed under the terms and conditions of the Creative Commons Attribution license (http://creativecommons.org/licenses/by/4.0/). 